\title{
Verzeichnis der verwendeten Siglen und Abkürzungen
}

\author{
Abb. Abbildung \\ ACA Barcelona, Arxiu de la Corona d'Aragó \\ ACB \\ ACRA \\ AHCB \\ $\mathrm{AHCG}$ \\ AHPB \\ AHPT \\ AMP \\ AMV \\ ARM \\ Arm. \\ Barcelona, Arxiu Capitular \\ Acta Curiarum Regni Aragonum \\ Barcelona, Arxiu Històric de la Ciutat \\ Girona, Arxiu Històric de la Ciutat \\ Barcelona, Arxiu Històric de Protocols \\ ARP \\ Teruel, Archivo Histórico Provincial \\ ARV \\ Palamós, Arxiu Municipal \\ València, Arxiu Municipal \\ Palma de Mallorca, Arxiu del Regne de Mallorca \\ Armadi \\ Arxiu del Reial Patrimoni \\ ASBM, MSCB \\ València, Arxiu del Regne \\ ASV \\ Canc. \\ Montserrat, Arxiu de Sant Benet, Fons del Monestir de Santa Clara \\ Città del Vaticano, Archivio Segreto Vaticano \\ Carp \\ CODOIN \\ Bd. 6 \\ Cancelleria \\ Carpeta \\ Colección de documentos inéditos del Archivo General de la Corona de Aragón \\ Procesos de las antiguas Cortes y parlamentos de Cataluña, Aragón y Valencia. \\ Ed. Próspero de Bofarull y Mascaró. (CODOIN 6) Barcelona 1850.
}

Bd. 32-34

Proceso contra Bernardo de Cabrera, mandado formar por el Rey Don Pedro IV. Ed. Manuel de Bofarull y de Sartorio. 3 Bde. (CODOIN 32-34) Barcelona 18671868.

Bd. 39 Rentas de la antigua Corona de Aragón. Ed. Manuel de Bofarull y de Sartorio. (CODOIN 39) Barcelona 1871.

Bd. 43

Privilegios reales concedidos a la ciudad de Barcelona. Ed. Antonio Maria Aragó/Mercedes Costa. (CODOIN 43) Barcelona 1971.

Bd. 45

Carte reali diplomatiche di Pietro IV il Cerimonioso. Re d'Aragona, riguardanti l'Italia. Ed. Luisa D’Arienzo. (CODOIN 45) Padua 1970.

Bd. 50 Actas de las Cortes Generales de la Corona de Aragón de 1362-63. Ed. José Maria Pons Guri. (CODOIN 50) Madrid/Barcelona 1982.

CRD

$\mathrm{db}$. Barcelona, Arxiu de la Corona d’Aragó, Cancelleria, Cartes reials diplomàtiques denarii barchinoneses/diners barchinonins

DCVB

Antoni Maria Alcover / Francesc de B. Moll, Diccionari català-valencià-balear. Inventari lexicogràfic i etimològic de la llengua catalana en totes les seves formes literàries i dialectals, recollides dels documents i textos antics i 

DHC Jesús Mestre i Campi (Hrsg.), Diccionari d’Història de Catalunya. Barcelona 31995.
dj. denarii jaccenses/denarios jaqueses
dm. denarii maioricenses/diners mallorquins
fl. florins d'or
G Sèrie General
JL Regesta Pontificum Romanorum ab condita ecclesia ad annum post Christum natum MCXCVIII., 2 Bde. Ed. Philipp Jaffé und bearb. von Samuel Löwenfeld / Ferdinand Kaltenbrunner / Paul Ewald. Leipzig 21885-1888.

Kap. Kapitel

LexMA

Robert-Henri Bautier u. a. (Hrsg.), Lexikon des Mittelalters, 10 Bde. München/Stuttgart/Weimar 1980-1999.

MGH Auct. Ant. 12 Cassiodori Senatoris Variae. Ed. Theodor Mommsen (MGH Auct. Ant. 12), Berlin 1894.

MGH Const. 5 Constitutiones et acta publica imperatorum et regum. Tomvs V. inde ab a. MCCCXIII. vsque ad a. MCCCXXIV. Ed. Jacob Schwalm. (MGH Const. 5) Hannover/Leipzig 1909-1913.

MGH Const. 11 Dokumente zur Geschichte des deutschen Reiches und seiner Verfassung 1354-1356. Ed. Wolfgang D. Fritz. (MGH Const. 11) Weimar 1978-1992.

MGH Epp. sel. 1 Die Briefe des heiligen Bonifatius und Lullus. Ed. Michael Tangl. (MGH Epp. sel. 1) Berlin 1916.

MR Mestre Racional

$\mathrm{OC}$ Joan Coromines (Hrsg.), Onomasticon Cataloniae. Els noms de lloc i noms de persona de totes les terres de llengua catalana, 8 Bde. Barcelona 1989-1997.

Perg. Pergamins

$r$

Recto

$\operatorname{Reg}$

Registres

RI

Regesta Imperii

$\mathrm{rm}$.

reials d'or de Mallorches

$\mathrm{sb}$.

solidi barchinonenses/sous barchinonins

sj. solidi jaccenses/sueldos jaqueses

sm. solidi maioricenses/sous mallorquins

Sp. Spalte

Tab. Tabelle

V verso

vgl. vergleiche

Vol.

Volum(s) 